\section{$\underset{\substack{\text { hommes } \\ \text { \& migrations }}}{ }$}

\section{Hommes \& migrations}

Revue française de référence sur les dynamiques

migratoires

1303 | 2013

Diasporas marocaines

\title{
Jean-Baptiste Harang, Bordeaux-Vintimille,
}

Paris, Grasset, 2012, 122 p., 12,10€.

\section{Mustapha Harzoune}

\section{(2) OpenEdition}

\section{Journals}

\section{Édition électronique}

URL : http://journals.openedition.org/hommesmigrations/2614

DOI : 10.4000/hommesmigrations.2614

ISSN : 2262-3353

\section{Éditeur}

Musée national de l'histoire de l'immigration

\section{Édition imprimée}

Date de publication : 1 juillet 2013

Pagination : 209-210

ISBN : 978-2-919040-23-0

ISSN : $1142-852 X$

\section{Référence électronique}

Mustapha Harzoune, « Jean-Baptiste Harang, Bordeaux-Vintimille, », Hommes \& migrations [En ligne], 1303 | 2013, mis en ligne le 22 janvier 2014, consulté le 22 septembre 2020. URL : http:// journals.openedition.org/hommesmigrations/2614; DOI : https://doi.org/10.4000/ hommesmigrations. 2614

Ce document a été généré automatiquement le 22 septembre 2020.

Tous droits réservés 


\title{
Jean-Baptiste Harang, Bordeaux- Vintimille,
}

Paris, Grasset, 2012, 122 p., 12,10€.

\author{
Mustapha Harzoune
}

\section{RÉFÉRENCE}

Jean-Baptiste Harang, Bordeaux-Vintimille, Paris, Grasset, 2012, 122 p., 12,10€.

1 Le train Bordeaux-Vintimille, le 14 novembre 1983. Trois candidats à la Légion étrangère assassinent Habib Grimzi. Uniquement et simplement parce qu'il était algérien. À l'époque des faits, Jean-Baptiste Harang a couvert ce drame pour le quotidien Libération. Trente ans plus tard, il livre un long reportage, un "récit" où seuls les noms des personnes ont été changés. Tout est présenté sans commentaires ni pathos. Jean-Baptiste Harang consigne des faits, réels pour l'essentiel, reconstitués ou “ déduits" pour une petite part. L'enquête progresse, depuis les éléments biographiques des protagonistes jusqu'aux procès, en passant par l'agression et la défenestration d'un jeune homme de 26 ans, ce 14 novembre 1983 à 0h20 du côté de... Castelsarrasin. Comme un pied de nez à l'histoire contrastée et entremêlée de cette terre et de ce peuple.

2 Sous la France de Giscard, celle aussi des premières années du septennat Mitterrand et de la montée du Front national, les crimes racistes se multipliaient. À l'époque nostalgiques de l'Algérie française ou pas -, on canardait le basané, à tire-larigot et sans trop de risques. Habib Grimzi, Rachid Abdou dans le livre, était en France comme touriste. Il se rendait à Bordeaux pour rencontrer sa correspondante scolaire. Un premier rendez-vous de trois jours pour une correspondance bihebdomadaire de près de six ans. Rachid Abdou s'en retournait en Algérie, heureux de sa rencontre avec Patricia, un peu déçu peut-être de sa brièveté. En croisant trois apprentis légionnaires, des gros bras imbibés d'alcool placés sous la responsabilité d'un caporal-chef, son nom allait grossir la liste des victimes du racisme antimaghrébin. 
3 Le texte rappelle que la Légion s'est toujours défaussée et que cette nuit-là, à l'exception de Vincent Perez alias ici Florent Lopez (le contrôleur), personne des quelque cent voyageurs-témoins n'osa intervenir, ou simplement tirer l'une des 26 poignées de signal d'alarme. Pas de procès en moraline ici, mais le rappel des faits à défaut de l'évocation du climat de ratonnade qui entourait cet assassinat. En 1983, le Lycée professionnel de Bois-Colombes avait décidé d'observer le 18 novembre quinze minutes de silence à la mémoire de Habib Grimzi. Quid en 2013 ?

4 On peut, comme l'auteur, s'interroger sur les mobiles des meurtriers et les circonstances du drame: racisme? violence gratuite? ivrognerie incontrôlée? biographies tourmentées et impasses existentielles des assassins? On peut multiplier les éclairages, chercher toutes les explications du monde ou, comme le fera l'un des avocats d'un assassin, réduire son client à un simple "exécutant", tout est envisageable et pourtant... on peut aussi être certain qu'il s'agit d'un crime raciste et rien d'autre. Si ces grands crimes ne doivent pas cacher ou dédouaner les "petits", ceux du racisme au quotidien (dixit l'auteur sur France Inter le 4 février 2013), dénoncer ce meurtre comme étant un crime raciste renferme aussi sa charge de sens - ne serait-ce que pour la victime et pour sa famille.

5 Jean-Baptiste Harang a choisi de changer les noms, pour le droit à l'oubli, quand la justice est passée. Il a dédié son récit à la mémoire de Habib Grimzi. Pour ne pas oublier. 